\title{
SPATIAL VARIABILITY OF HUMAN HEALTH IMPACTS: APPLICATION TO A BIOREFINERY PROCESS IMPLEMENTATION
}

\author{
Bratec, Florian (1,2); Bratec, Tatiana (1); Marty, Pauline (1); Troussier, Nadege (1); Diaz- \\ Pichardo, Rene (1,3)
}

1: University of Technology of Troyes; 2: Altermaker; 3: Y Schools

\begin{abstract}
More and more attention is paid nowadays to the human health concerns, associated with environmental problems arising from the fossil fuel use. The world scientific community offers new alternatives that, despite being more environmentally friendly, require an analysis of their potential environmental impacts. For example, biorefineries are becoming increasingly widespread nowadays offering a large gamma of bio-based products. However, it is necessary to take into account what potential effects such facility may have on the human health, depending on its geographical location since different territories may be more or less sensitive to its installation. Our study describes a new bioprocess implementation in terms of impact on human health through three countries: France, Belgium or China. In order to understand what territory can be more appropriate to the industrial process installation in terms of its effects on the human health, we propose to use the spatialized life-cycle analysis methodology.
\end{abstract}

Keywords: Process modelling, Research methodologies and methods, Case study, Sustainability, Ecodesign

Contact:

Bratec, Tatiana

University of Technology of Troyes

CREIDD

France

tatiana.bratec@utt.fr

Cite this article: Bratec, F., Bratec, T., Marty, P., Troussier, N., Diaz-Pichardo, R. (2019) 'Spatial Variability of Human Health Impacts: Application to a Biorefinery Process Implementation', in Proceedings of the 22nd International Conference on Engineering Design (ICED19), Delft, The Netherlands, 5-8 August 2019. DOI:10.1017/dsi.2019.104 


\section{INTRODUCTION}

The global community deals nowadays with several serious challenges, including among others environmental ones (e.g. air quality, climate change ...) appeared, mostly, because of intensive fossil fuel use (Cherubini, 2010). To minimize ecological impacts on the environment and to guarantee a well-being of the humanity, a search of alternative sources has been launched.

In a design context, the choice of the sites of manufacturing is a crucial step. This selection depends on the needed processes to shape the product and has an influence on many aspects of the value chain as the technical feasibility, the economic goals, the risk management or the productivity. In the ecodesign context, it is also about environmental impacts. The choice of a manufacturing process implies the choice of its geographical location and induces a spatial variability of the related impacts.

In this study, a biorefinery concept is regarded as an alternative solution to fossil resources, allowing the use of biomass in the industrial production of energy and non-energy sectors (Demirbas, 2001; Fernando et al., 2006; Field et al., 2008). The development of new biorefinery facilities, supported by regulatory policies at national, regional and local levels, has started rather recently, however the number of biorefineries is increasingly growing (Yazan et al., 2017). Thus, based on the Colognebased nova-Institute data, 224 biorefineries of different types operated, and several dozen more were under construction in 2017 only across European countries (De Guzman, 2017).

Studies show that biorefineries have lower environmental impact comparing to the petrochemical complexes within several aspects. e.g. reduction in global warming emissions (Dale, 2003; Cherubini, 2010). Nevertheless, even though their impact is less significant, it cannot be neglected in environmental impact studies. Emissions, associated with a biorefinery facility, could be generated at its different value/supply chain stages, from the feedstock cultivation through production stage to the bio-product disposal. To minimize the environmental impacts of industrial processes and products through their entire life cycles, the application of the eco-design approach is regarded as powerful tool (Cobut et al., 2015). Eco-design can be seen as a strategic design activity in order to develop sustainable solutions and to put into practice the principles of sustainability, namely green chemistry and sustainable process engineering, aiming at ensuring less environmental pollution and contributing to health and environmental progress.

Being an integral part of the eco-design approach, life-cycle assessment (LCA) is currently one of the most commonly used methods to assess environmental impacts of industrial processes and products, namely of the biorefinery sector (Caldeira-Pires et al., 2013; Caffrey et al., 2014; Ahlgren et al., 2015; Tonini et al., 2016). Numerous studies, revealing the estimation of biorefinery environmental impacts, have focused mostly on the environmental problems (LCA midpoint impact indicators), such as global warming, acidification, eutrophication, water and land uses (Ekman et Börjesson, 2010; Börjesson and Tufvesson, 2011; González-García et al., 2011; Gnansounou et al., 2015; Chrysikou et al., 2018). However, a poor attention is given to the final environmental consequences (LCA endpoint impacts) of these effects, for example to the human health. In addition, despite the fact that LCA is one of the most widespread tools for environmental impact modelling, its major limitation is a lack of commonly accepted methodology on spatial differentiation consideration. Without the spatial aspects considered, LCA results on environmental impacts of the same industrial process, integrated to various geographical areas will be identic. Indeed, since the geographical variability of territories is different, and each area is more or less sensitive and is more or less resilient in terms of potential environmental damage (Bratec et al., 2017), the environmental impacts are influenced, to a great extent, by a geographical location. Therefore, the following question is raised in this study: how to account for the spatial variability of environmental impacts on human health in the context of industrial production?

This study presents a proof-of-concept of human health impact variability, based on spatialized lifecycle assessment of industrial production. The proposed methodology is implemented at the national level on the example of three countries (France, Belgium and China). The results obtained are targeted to demonstrate environmental patterns of industrial activity within different geographical contexts. This could have an influence on the decision choice, for example, in the selection of optimal location of the industrial process facility, based on its environmental performance. 


\section{LIFE-CYCLE ASSESSMENT: A SHORT LITERATURE REVIEW}

Life-cycle assessment is a method allowing evaluating the potential environmental impact of a product or a service over its entire lifetime, i.e. from raw material extraction to the end-of-life. LCA methodology is standardized by the International Organization for Standardization in ISO 14040/14044, according to which it is carried out in four main phases: goal and scope definition, life-cycle inventory assessment, life-cycle impact assessment and life-cycle interpretation (Finkbeiner et al., 2006).

The development of LCA begun in the 1960th when environmental degradation along with limited resource access started becoming an important concern. LCA methodology found a broad application in decision supporting within the environmental sustainability context due to numerous initiatives launched at national and international levels (UNEP, SETAC, ...) in order to facilitate and support its application (Bjørn et al., 2018). Nowadays LCA, covering wide range of domains (energy sector, building industry, agriculture, waste management and others), is widely used within the environmental studies (Góralczyk, 2003; Perminova et al., 2016; Tricase et al., 2017; Hossain et al., 2017; El Hanandeh et al., 2017; Dijkman et al., 2018).

\subsection{Spatial dimension in life-cycle assessment}

LCA, designed at the base for the global pollution prevention, did not take into account spatial dimension in its methodology (Potting and Hauschild, 2006). However, the importance of its consideration was rapidly recognised by the scientific community since the integration of geographical location to the LCA studies allowed increasing representativeness and reliability of the environmental impact results (Mutel and Hellweg, 2009). Despite the fact that particular attention is currently paid to the questions of integration of geographic aspects to LCA, there is no one commonly accepted methodology allowing integrating geographical variations at every LCA stage.

A recent review of Patouillard et al. (2018) presents a rather complete critical analysis and practical recommendations on how to integrate the spatial aspects into life-cycle assessment. According to the authors, the geographic aspects could be considered at all LCA phases: from the goal and scope definition to the interpretation stage. In order to integrate the spatial dimension in goal and scope phase, a territorial LCA approach should be adopted and spatial information should be used. For the inventory regionalization, two current and complementary practices are identified: process recontextualization (adaptation of a unit process to be more representative of an expected geographical coverage) and adaptation of numerical data within a process to better reflect its representativeness of a given geographical coverage. Various data sources could be used for the geographical representativeness improvement such as specific on-site data collection, regionalized statistical data, LCI databases and others. However, it is important to identify the priority data to be regionalized as well as the level of details required. Besides, the quality of this data must be evaluated to estimate the overall uncertainty. As for the inventory spatialization, allowing to identify the contribution of geographic zones to impact scores, the inventory could be spatialized at the process level or at the Effect Factor (EF) level. For the latter, different geographical information can be added, depending on the LCA software and the LCIA method used (textual information on the geographical zone of the EF, archetype description associated with the EF or geographic coordinates may be used to localize the EF). For the integration of regionalization in impact calculations, impact scores must be calculated at each location with the respective regionalized Characterization Factors $(\mathrm{CFs})$ before any aggregation. For the integration of regionalization in LCIA methods, it is possible to develop regionalized (or spatially differentiated) CFs by two approaches: the archetype approach and the spatial differentiation approach. In addition, several approaches are also presented by the authors in order to integrate the spatial dimension during the interpretation phase.

More and more regionalized LCI databases and LCIA methods have been recently developed. Among existing LCIA methods/models considering spatial aspects, the following ones can be cited: ReCiPe, Impact World+, Impact 2002+, CML 2001, Eco-indicator 99, LC-IMPACT, TRACI, EDIP 2003, USEtox. Each of these methods has its spatial coverage, i.e. an area of the geographic validity. Patouillard et al. (2018), for instance, consider IMPACT World+ and LC-IMPACT to be the most appropriate methods to use for the impact regionalization assessment. However, in our opinion, the main driven force of the method selection is its correspondence to the study objective. 


\subsection{Human health in life-cycle assessment}

In LCA, environmental impacts are considered through two categories: midpoint-oriented and endpoint oriented. The midpoint-oriented impacts are commonly representative of environmental problems: they quantify an effect, but not a consequence. For instance, $\mathrm{CO} 2$ emissions (environmental problem) represent the global warming (effect). The end-point oriented impacts are representativeness of the environmental damage, i.e. a final consequence: the global warming leads to the climate change (Bratec et al., 2017). Several midpoint impact categories may contribute to one endpoint impact.

Human health could be affected by the environmental pollution in different ways. For example, the effects of climate change on human health could be the following: heat waves, air pollution, spread of water borne or vector-borne infectious diseases; the effects of ozone layer depletion: increased risk of skin cancer and cataracts; the effects ionising radiation: cancer and hereditary effects; the effects of particulate matter: respiratory health damage. Human health corresponds to end-point category in LCA and aims to quantify the changes in both mortality and morbidity. Two concepts are considered for human health impact indicator: the DALY-concept (Disability Adjusted Life Years) and the QALY concept (Quality Adjusted Life Years), however the first one is selected as the most appropriate metric (ILCD Handbook, 2010).

According to ILCD Handbook (2017), such midpoint impacts as climate change, ozone depletion, human toxicity, respiratory organics, ionising radiation and photochemical ozone formation are considered to contribute to damages on human health. However, the range of midpoint impact categories included to the human health damage varies from one LCIA method to another (Figure 1). For example, in ReCiPe the damage to human health includes climate change, human toxicity, ozone layer depletion, ionising radiation, water use, photochemical oxidant and particulate matter formations (Huijbregts et al., 2017). Impact World+ includes climate change, human toxicity, ozone layer depletion, ionising radiation, water use/stress and respiratory effects (Impact World+ publications). Impact 2002+ involves all discussed in Figure 1 impact categories except for the particulate matter formation (Humbert et al., 2012). CML 2001 and Eco-indicator 99 include both five indicators. The first one comprises climate change, human toxicity, ozone layer depletion, ionising radiation and photochemical oxidant formation (Heijungs, 2018), while the second one comprises the first four, but instead of photochemical oxidant formation, it includes respiratory effects (Goedkoop and Spriensma, 2001). LC-IMPACT includes climate change, ozone layer depletion, ionising radiation, photochemical oxidant formation, water use/stress and particulate matter formation (Verones et al., 2016). TRACI comprises climate change, human toxicity, ozone layer depletion, photochemical oxidant formation and particulate matter formation (Bare, 2012). The least number of categories is taken into consideration in EDIP 2003 (Hauschild and Potting, 2005) and USEtox (Rosenbaum et al., 2008): 4 categories (climate change, human toxicity, ozone layer depletion and photochemical oxidant formation) and 1 category (human toxicity), respectively.

\section{MATERIALS AND METHODS}

\subsection{Case study}

A consortium of industrial actors defined a new bio-based process in order to create biomolecules from sunflower feedstock. The industrial process includes the following steps: (1) preparation, (2) heat, (3) treatment and purification and (4) conditioning. It is actually at the sixth level within the Technology Readiness Level (TRL) context, and the next development phases imply the study of its industrial production from a lab- to a biorefinery-scale. The industrial process location is not identified. Three countries are considered as candidate places for the process installation: France, Belgium and China. This choice is explained by the fact that these countries possess the equipment capable to resist to the temperature and pressure conditions of the process. The crucial criteria of the process final emplacement choice is the minimal impact of the studied process to the human health.

\subsection{LCIA method selection}

To choose one LCIA method that is the most appropriated to the objective of our study, we based on the results of the literature review on the existing LCIA methods, allowing evaluating spatialized human health impacts (Figure 1). 
The most important method selection criterion is the consideration of the maximum number of possible impact categories that contribute to the damage to human health. As can be seen from Figure 1, only four LCIA methods include spatial dimension: Impact World+, LC-IMPACT, EDIP 2003 and USEtox. Impact World+ and LC-IMPACT comprise three impact categories, while EDIP 2003 and USEtox include two categories and one category, respectively. However, Impact World+ takes into account the spatial aspect at two different scales that is not applicable within our case study, focused entirely on the national scale. Therefore, only LC-IMPACT method is pertinent for our study.

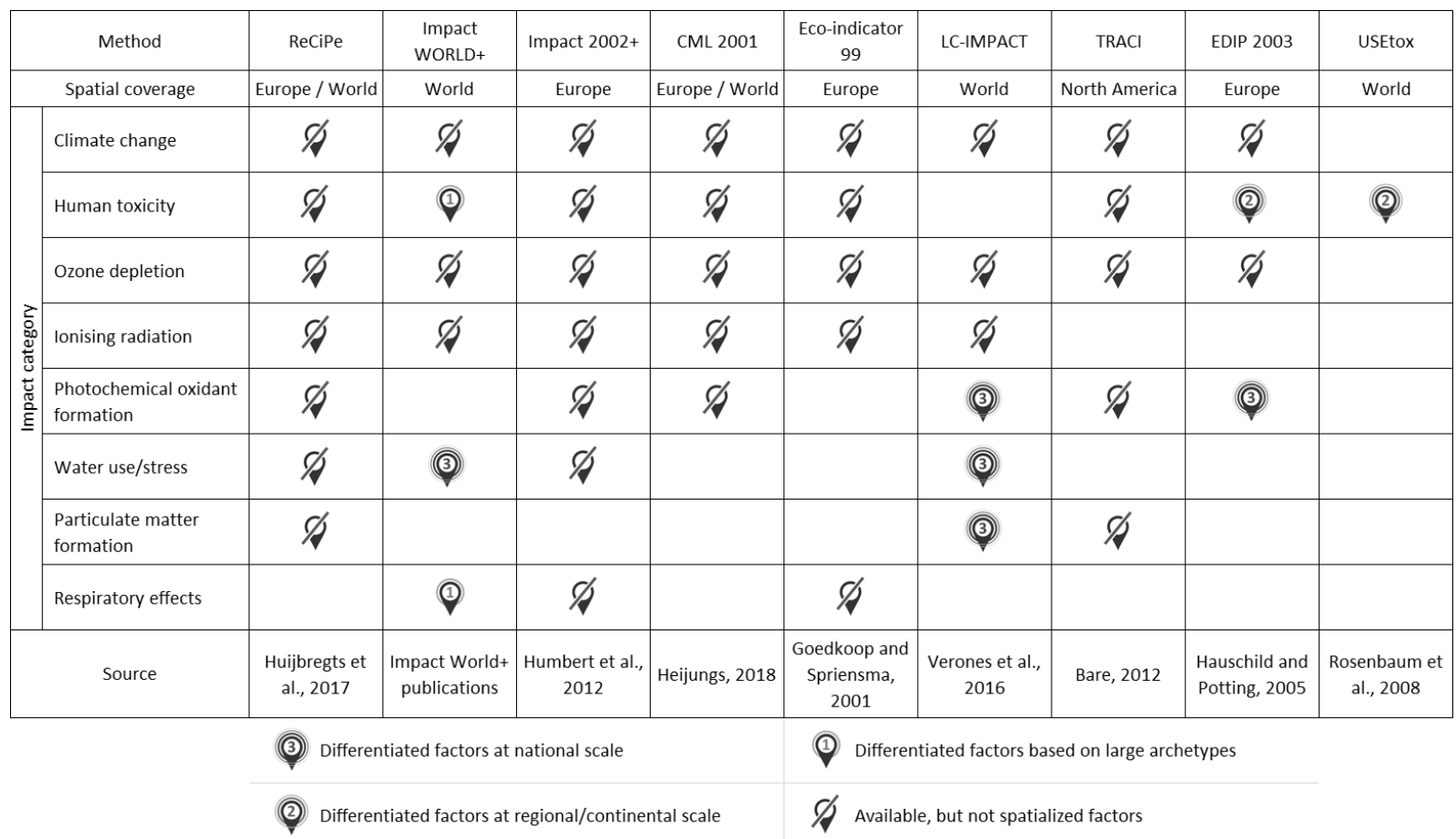

Figure 1. Consideration of spatial dimension and human health impacts in different LCIA methods (performed by the authors based on literature sources)

\section{RESULTS AND DISCUSSION}

Considering the use of the LC-IMPACT assessment method to model the potential impact of the process on human health, we note the need to characterize 6 flows:

- Particulates $<2.5 \mu \mathrm{m}$ (kg PM2.5) - contribute to Particulate matter formation

- Ammonia (kg NH3) - contributes to Particulate matter formation

- Sulfur dioxide (kg SO2) - contributes to Particulate matter formation

- Nitrogen oxides (kg NOx) - contribute to Particulate matter formation and Photochemical ozone formation

- Non-methane volatile organic compounds (kg NMVOC) - contribute to Photochemical ozone formation

- Water use (m3) - contributes to Water stress

In order to obtain these quantified flows, the openLCA software was used on the basis of the process modelling, carried out with the consortium of industrial actors. Once these flows were characterized, using the factors we isolated from the LC-IMPACT method, the following results were obtained. 


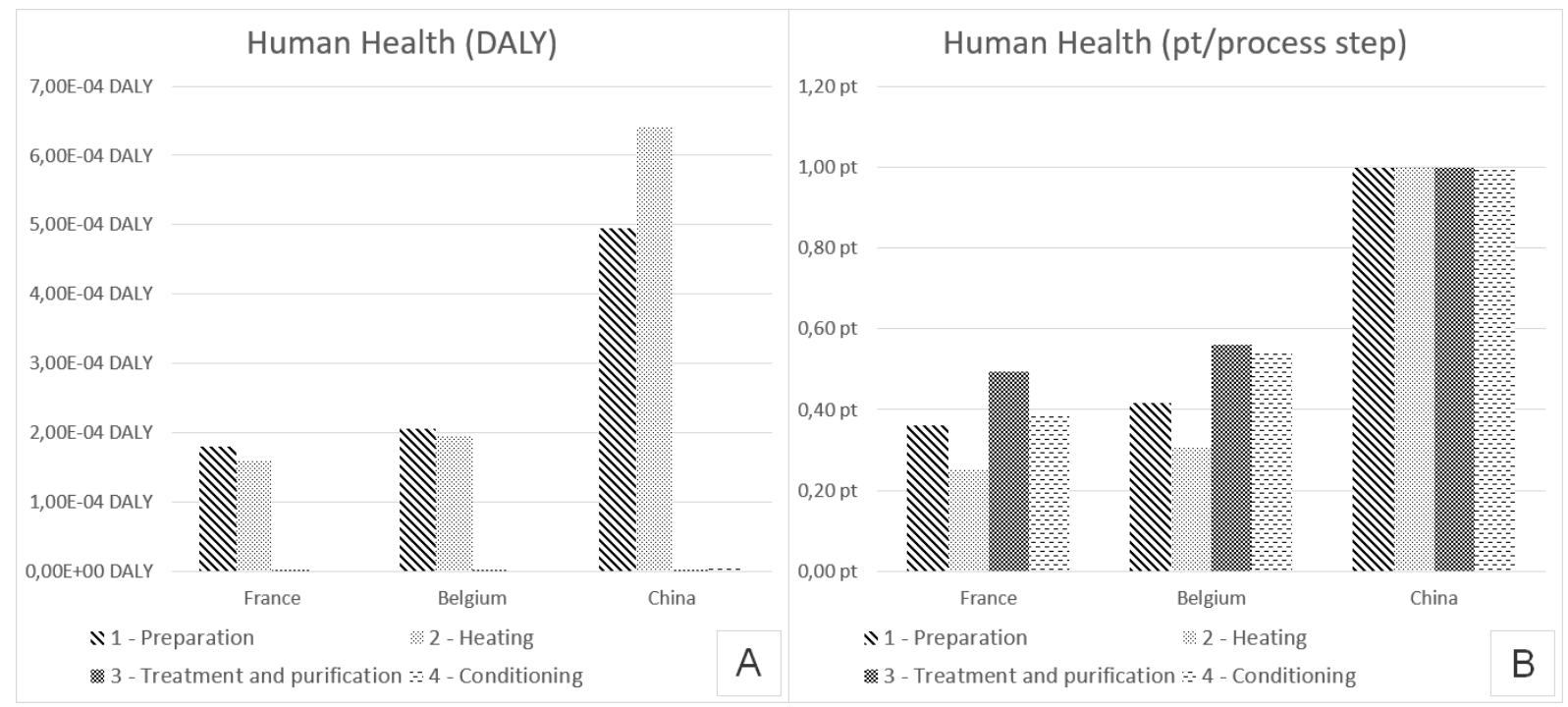

Figure 2. Spatially differentiated characterization of human health impact

In Figure 2A, it can be seen that the impact of the process implementing in China would be three times higher than in Belgium or France. Indeed, the total impact of the process (in DALY) would be 11.38E04 in China, against 4.03E-04 in Belgium and 3.41E-04 in France. Regardless of the territory of implantation, steps 1 and 2 of the process (Preparation and Heating) concentrate about $99 \%$ of the total impact. In Figure 2B, it can be seen that at each stage of the process, the potentially most impactful location remains China. As for the location with the least impact, it is France for each step.

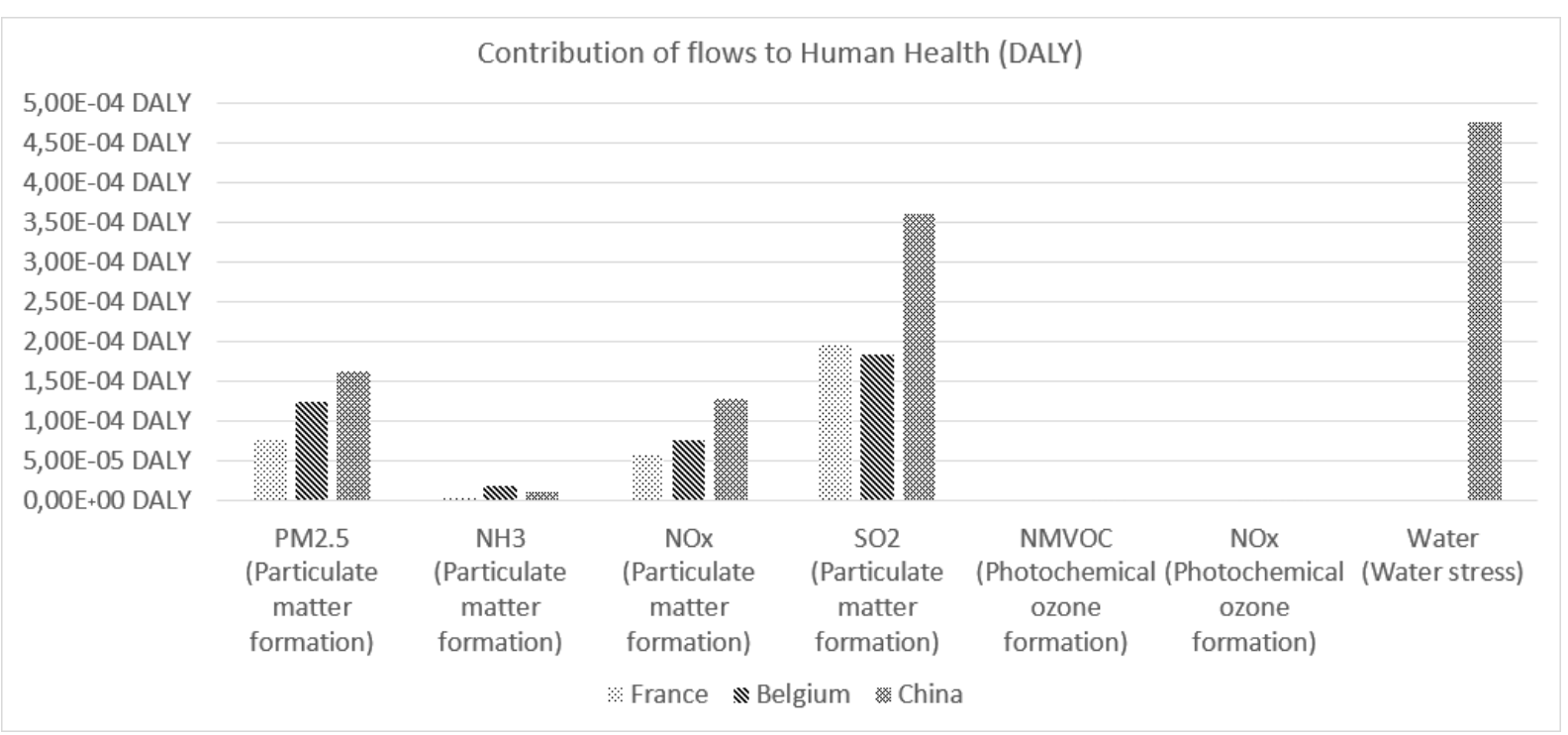

Figure 3. Contribution of flows to human health

In Figure 3, we can observe that the main contribution to the impact on human health comes from particulate matter formation (PM2.5, NH3, NOx and SO2). A large contribution to the water stress impact is also to be noted on the results for Chinese territory. This high potential impact related to water stress is due to a damage factor used in the calculation method. This damage factor is based on the rate of malnutrition on the territory: for this reason, although this rate is not extreme in China, it is relatively much higher than in France and Belgium where it is zero.

Although the contribution of water stress to the impact on human health is very high for China, the contribution to other flows is also and globally higher than two other territories. Five out of the seven considered flows are characterized by a higher impact on Chinese territory. The other two flows (NH3 and NOx for Photochemical ozone formation) have their highest impact located in Belgium. Five out of the seven considered flows are characterized by a lower impact in France. Two other flows for which the impact is less (SO2 and NMVOC) are located in Belgium. 
The observed variations on the total impact go up to $334 \%$. These variations are mainly due to the contribution of particulate matter formation. They are explained, in particular, by the change in exposure to particulates, depending on the region. The different types of populations and especially the age distribution determine the intake fraction of particulates and, therefore, characterize the severity of the impact.

In view of these results, some limitations are to be pointed with regard to the size of the different geographical scales studied. Indeed, Belgium $\left(\sim 30,000 \mathrm{~km}^{2}\right)$, France $\left(\sim 640,000 \mathrm{~km}^{2}\right)$ and China $(\sim$ $9,600,000 \mathrm{~km}^{2}$ ) have differences in extent that puts into question their comparability. On a territory as vast as China, geographical disparities are high: for example, variations in population densities within the territory induce a strong uncertainty on the observed results.

In addition to these geographical disparities, a limitation, regarding the fate of the emitted substances, has to be considered. The country boundaries do not match with substance transport distances by air, water and soil. According to Greco et al. (2007), the median distance to half of the exposure is reached at $150 \mathrm{~km}$ for PM2.5, $390 \mathrm{~km}$ for SO2 and $450 \mathrm{~km}$ for NOx. This means that at a scale as vast as the Chinese territory, it is relevant to conclude on the spatial impact on human health. However, for a territory like Belgium, the scale of the impact is obviously more extended and can also concern border countries such as France, Luxembourg, the Netherlands or Germany. To respond to these limitations, a possible approach would be a sensitivity analysis in order to combine the characterization factor of the country where the impact occurs with those from the border countries, with several weightings. Nevertheless, such an analysis is relevant only for small countries and varies depending on the studied substances.

Figure 4 presents a sensitivity analysis example, where an emission source of PM2.5 is defined in the centre of Belgium. A median radius of exposure of $150 \mathrm{~km}$ is considered to adjust the characterization factor of the impact. The factor of each border country is weighted depending on the potentially impacted area (in $\mathrm{km}^{2}$ ).

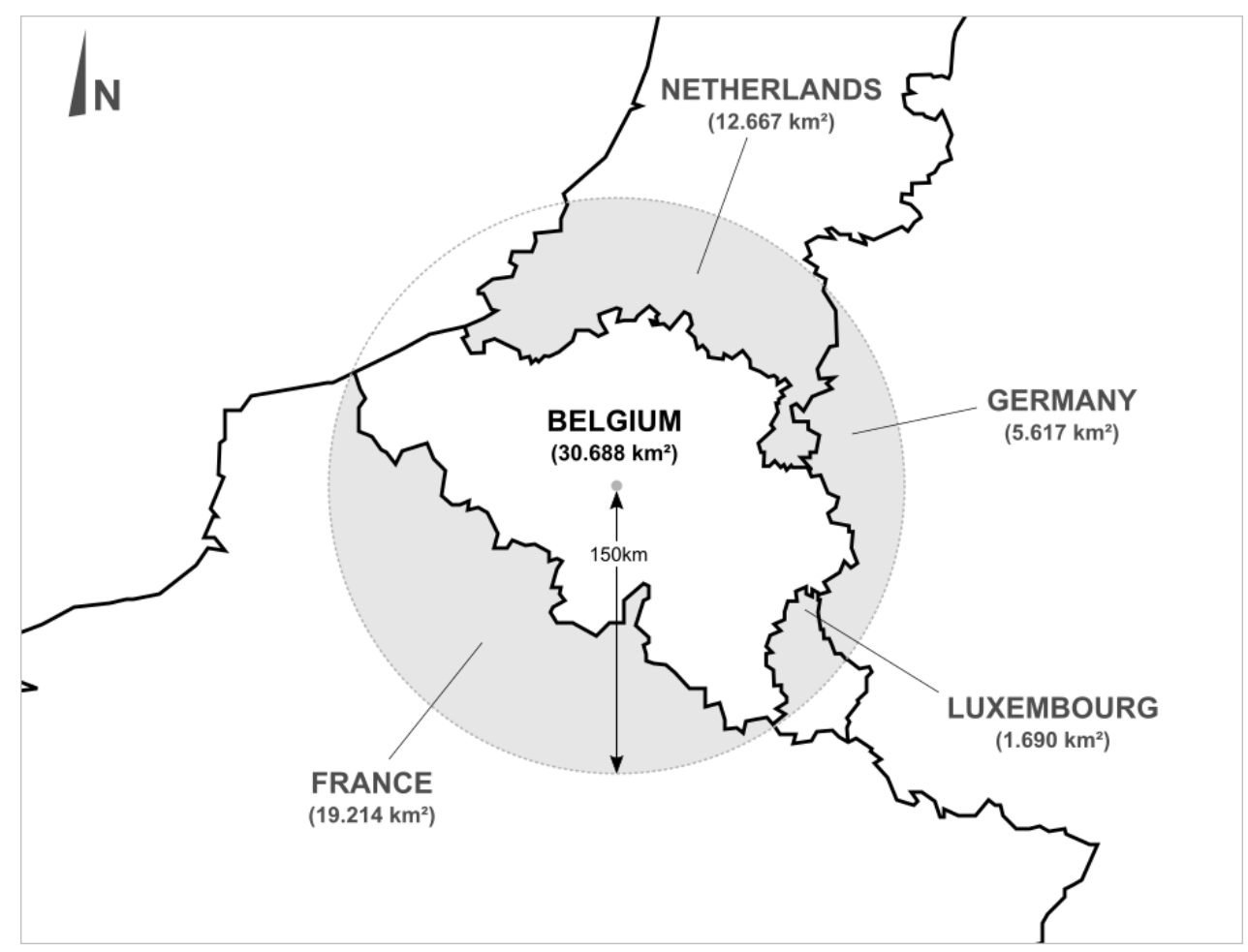

Figure 4. Considered area for characterization factors weighting

This adjusted calculation allows to notice that a less severe impact due to emission of PM2.5 in Belgium is more realistic. The impact focused only on Belgian territory is $50 \%$ higher than the impact on the area of $150 \mathrm{~km}$ radius with a centre located in Belgium (Figure 5). This sensitivity analysis could also be led on the other substances with other radiuses. However, it should be noted that no any meteorological parameters (e.g. wind direction) were taken into account for the presented sensitivity analysis that presents the limitation. 


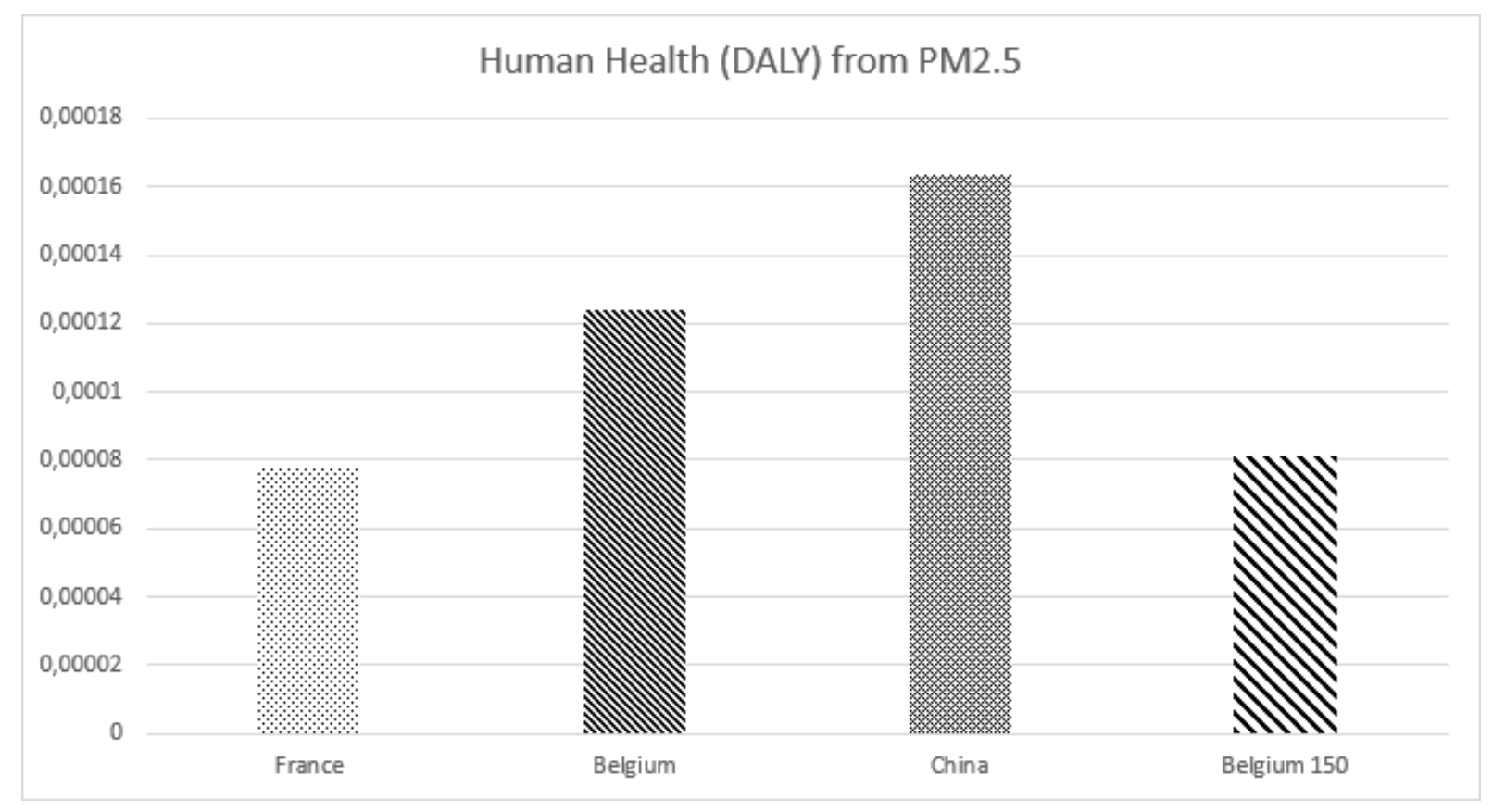

Figure 5. Contribution of PM2.5 to Human Health impact for Belgium adjusted to $150 \mathrm{~km}$

We would rather recommend the development of finer characterization factors, regardless of national borders. This approach would allow more realistic simulations, considering the fate of each substance implied in the impact. In a design context, only this methodology improvement could allow to compare several manufacturing sites in the same country.

\section{CONCLUSION}

Through this study, the potential impacts on human health related to the implementation of the biorefinery industrial process were simulated at three different territories. These territories, selected because of their respective technological capabilities to host the start of the process production, are France, Belgium and China. The modelling of the process made it possible to obtain a quantified flow inventory to be characterized. Given the objectives of the study, focusing on the impacts on human health and taking into account the geographical variability, the LC-IMPACT assessment method was chosen. The main conclusion of this article lies in the importance of considering the spatial variability of an impact such as human health when putting into production an industrial process. Indeed, the implementation of such process opens a range of options selected on technological and economic criteria. These options, guaranteeing the feasibility of scaling up, can then be ranked according to their potential impact. This study highlights a $334 \%$ variation in impact depending on the selected location: China is the region where the damage to human health would be the highest with $11.38 \mathrm{E}-04$ disabilityadjusted life years (DALY). In addition, the results also reveal that the two aggravating factors are related to water stress, in particular due to higher malnutrition rates in China comparing to France or Belgium, and higher particulate exposure, due to the typology of the population.

In a design context, in particular, with eco-design goals, the choice of manufacturing sites (including all processes needed in the value chain) is a crucial step. The geographical location of each of these processes implies variability of the impacts and this study illustrates it on the example of the biorefinery process.

While the conclusions of this study clearly highlight the need to integrate LCA into the choices related to industrial production, they also reveal a lack of available methodologies to ensure the comparability of the studied territories. In this case study, Belgium is compared to China (320 times the area of the Belgian territory). It then becomes obvious that the geographical disparities of such extensive territories imply strong uncertainties on the calculations of impacts. A perspective of this work then emerges in the adaptation of the method used to refine the scales through, for example, a downscaling approach that would allow simulations more faithful to the studied issues. 


\section{REFERENCES}

Bare, J. (2012), Tool for the Reduction and Assessment of Chemical and other Environmental Impacts (TRACI), US EPA.

Bjørn, A., Owsianiak, M., Molin, C. and Hauschild, M. Z. (2018), LCA History, Springer, Cham. https://doi.org/10.1007/978-3-319-56475-3_3

Börjesson, P. and Tufvesson, L. M. (2011), “Agricultural crop-based biofuels-resource efficiency and environmental performance including direct land use changes", Journal of Cleaner Production, Vol. 19 No. 2-3, pp. 108-120. https://doi.org/10.1016/j.jclepro.2010.01.001

Bratec F., Troussier N. and Diaz-Pichardo R. (2018), "Toward the creation of an impact seriousness indicator to assist the designer", In Press.

Cherubini, F. (2010), "The biorefinery concept: using biomass instead of oil for producing energy and chemicals", Energy conversion and management, Vol. 51 No. 7, pp. 1412-1421. https://doi.org/10.1016/j.enconman.2010.01.015

Chrysikou, L. P., Bezergianni, S. and Kiparissides, C. (2018), "Environmental analysis of a lignocellulosic-based biorefinery producing bioethanol and high-added value chemicals", Sustainable Energy Technologies and Assessments, Vol. 28, pp. 103-109. https://doi.org/10.1016/j.seta.2018.06.010

Cobut, A., Beauregard, R. and Blanchet, P. (2015), "Reducing the environmental footprint of interior wood doors in non-residential buildings-part 2: ecodesign", Journal of Cleaner Production, Vol. 109, pp. 247259. https://doi.org/10.1016/j.jclepro.2015.05.068

Dale, B. E. (2003), “'Greening' the chemical industry: research and development priorities for biobased industrial products", Journal of Chemical Technology \& Biotechnology, Vol. 78 No. 10, pp. 1093-1103. https://doi.org/10.1002/jctb.850

De Guzman, D. (2017), Map of European Biorefineries [online]. Available at: https://greenchemicalsblog.com/2017/11/29/map-of-european-biorefineries/ (accessed 12/20/2018).

Demirbaş, A. (2001), "Biomass resource facilities and biomass conversion processing for fuels and chemicals", Energy conversion and Management, Vol. 42 No 11, pp. 1357-1378. https://doi.org/10.1016/S01968904(00)00137-0

Dijkman, T. J., Basset-Mens, C., Antón, A. and Núñez, M. (2018), “LCA of Food and Agriculture”, In: Hauschild M., Rosenbaum R., Olsen S. (eds), Springer, Cham, pp. 723-754. https://doi.org/10.1007/978-3319-56475-3_29

Ekman, A. and Börjesson, P. (2011), "Environmental assessment of propionic acid produced in an agricultural biomass-based biorefinery system”, Journal of Cleaner Production, Vol. 19 No. 11, pp. 1257-1265. https://doi.org/10.1016/j.jclepro.2011.03.008

El Hanandeh, A., Gilbert, B. and Bailleres, H. (2017), “A comparative life-cycle assessment (LCA) of alternative material for Australian building construction", 1st International Conference on Advances in Sustainable Construction Materials and Civil Engineering Systems, ASCMCES 2017, MATEC Web of Conferences, p. 9. https://doi.org/10.1051/matecconf/201712002013

Fernando, S., Adhikari, S., Chandrapal, C. and Murali, N. (2006), "Biorefineries: current status, challenges, and future direction”, Energy \& Fuels, Vol. 20 No. 4, pp. 1727-1737. https://doi.org/10.1021/ef060097w

Field, C. B., Campbell, J. E. and Lobell, D. B. (2008), "Biomass energy: the scale of the potential resource", Trends in ecology \& evolution, Vol. 23 No. 2, pp. 65-72. https://doi.org/10.1016/j.tree.2007.12.001

Finkbeiner, M., Inaba, A., Tan, R., Christiansen, K. and Klüppel, H. J. (2006), "The new international standards for life-cycle assessment: ISO 14040 and ISO 14044”, The international journal of life-cycle assessment, Vol. 11 No. 2, pp. 80-85. https://doi.org/10.1065/lca2006.02.002

Gnansounou, E., Vaskan, P. and Pachón, E. R. (2015), "Comparative techno-economic assessment and LCA of selected integrated sugarcane-based biorefineries”, Bioresource technology, Vol. 196, pp. 364-375. https://doi.org/10.1016/j.biortech.2015.07.072

Goedkoop, M. J. and Spriensma, R. (2001), The Eco-indicator 99 : A damage oriented method for Life-cycle Impact Assessment, Methodology Report, Pre Concultants, the Netherlands.

González-García, S., Hospido, A., Agnemo, R., Svensson, P., Selling, E., Moreira, M. T. and Feijoo, G. (2011), "Environmental life-cycle assessment of a Swedish dissolving pulp mill integrated biorefinery", Journal of industrial ecology, Vol. 15 No. 4, pp. 568-583. https://doi.org/10.1111/j.1530-9290.2011.00354.x

Góralczyk, M. (2003), "Life-cycle assessment in the renewable energy sector", Applied Energy, Vol. 75 No. 3-4, pp. 205-211. https://doi.org/10.1016/S0306-2619(03)00033-3

Greco, S. L., Wilson, A. M., Spengler, J. D. and Levy, J. I. (2007), "Spatial patterns of mobile source particulate matter emissions-to-exposure relationships across the United States", Atmospheric Environment, Vol. 41 No 5, pp. 1011-1025. https://doi.org/10.1016/j.atmosenv.2006.09.025

Handbook, I. L. C. D. (2010), "Framework and requirements for LCIA models and indicators". JRC, European Commission.

Hauschild, M. and Potting, J. (2005), "Spatial differentiation in Life-cycle impact assessment-The EDIP2003 methodology”, Environmental news, Vol. 80, p. 195. 
Heijungs, R. (2018), CMLCA: scientific software for LCA, IOA, EIOA, and more. Available at http://cmlca.eu/ (accessed 16/12/2018).

Hossain, M. U., Poon, C. S., Lo, I. M. and Cheng, J. C. (2017), "Comparative LCA on using waste materials in the cement industry: A Hong Kong case study”, Resources, Conservation and Recycling, Vol. 120, pp. 199-208. https://doi.org/10.1016/j.resconrec.2016.12.012

Huijbregts, M. A., Steinmann, Z. J., Elshout, P. M., Stam, G., Verones, F., Vieira, M., Zijp, M., Hollander, A. and van Zelm, R. (2017), "ReCiPe2016: a harmonised life-cycle impact assessment method at midpoint and endpoint level”, The International Journal of Life-cycle Assessment, Vol. 22 No. 2, pp. 138-147. https://doi.org/10.1007/s11367-016-1246-y

Humbert, S., De Schryver, A., Bengoa, X., Margni, M. and Jolliet, O. (2012), IMPACT 2002+: User Guide Draft for version $Q 2.21$ (version adapted by Quantis), Quantis, Lausanne, Switzerland.

IMPACT World + publications. Available at http://www.impactworldplus.org/en/publications.php (accessed 16/12/2018).

Mutel, C.L. and Hellweg, S. (2009), "Regionalized life-cycle assessment: computational methodology and application to inventory databases”, Environmental Science and Technology, Vol. 43 No. 15, pp. 57975803. https://doi.org/10.1021/es803002j

Patouillard, L., Bulle, C. and Margni, M. (2016), "Ready-to-use and advanced methodologies to prioritise the regionalisation effort in LCA”, Matériaux \& Techiques, Vol. 104 No. 1, p. 105. https://doi.org/10.1051/mattech/2016002

Perminova, T., Sirina, N., Laratte, B., Baranovskaya, N. and Rikhvanov, L. (2016), "Methods for land use impact assessment: a review”, Environmental Impact Assessment Review, Vol. 60, pp. 64-74. https://doi.org/10.1016/j.eiar.2016.02.002

Potting, J. and Hauschild, M. (2006), "Spatial differentiation in life-cycle impact assessment: a decade of method development to increase the environmental realism of LCIA", The international journal of life-cycle assessment, Vol. 1, pp. 11-13. http://dx.doi.org/10.1065/lca2006.04.00

Tricase, C., Lamonaca, E., Ingrao, C., Jacopo, B. and Agata, L. G. (2017), “A comparative Life-cycle Assessment between organic and conventional barley cultivation for sustainable agriculture pathways", Journal of Cleaner Production, Vol. 172, pp. 3747-3759. https://doi.org/10.1016/j.jclepro.2017.07.008

Verones, F., Hellweg, S., Azevedo, L.B., Chaudhary, A., Cosme, N., Fantke, P., Goedkoop, M., Hauschild, M., Laurent, A., Mutel, C.L., Pfister S., Ponsioen, T., Steinmann Z., van Zelm, R., Vieira M. and Huijbregts, M.A.J. (2016), LC - Impact (Version 0.5), A spatially differentiated life-cycle impact assessment approach. Available at : http://lc-impact.eu/downloads/documents/LCImpact_report_SEPT2016_20160927.pdf (accessed 16/12/2018)

Yazan, D. M., Mandras, G. and Garau, G. (2017), "Environmental and economic sustainability of integrated production in bio-refineries: The thistle case in Sardinia", Renewable energy, Vol. 102, pp. 349-360. https://doi.org/10.1016/j.renene.2016.10.055 